16 a 18 de outubro de 2019 - Campinas | Brasil

\title{
Avaliação das características do fosfogesso na reciclagem
}

\section{Janaina D. Souza*; Gladis Camarini.}

\section{Resumo}

Devido ao grande volume de resíduos gerados na indústria, a procura por de métodos de reaproveitamento de resíduos, e a utilização de materiais menos poluentes faz-se cada vez mais necessária. O fosfogesso é um resíduo da indústria de fertilizantes que possui características físicas e químicas semelhantes ao do gesso de origem natural, e vem sendo apontado como uma alternativa para a substituição do gesso na construção civil. O presente trabalho teve como objetivo avaliar a melhor forma de realizar a reciclagem do fosfogesso para utilização como aglomerante. Para tanto o fosfogesso foi reciclado em diferentes períodos de permanência no forno, foi submetido a ensaios físicos e mecânicos, e os resultados comparados com o gesso comercia. Os resultados indicam que a calcinação por um período de 2 horas torna o produto viável para a reciclagem e aplicação na construção civil.

\section{Palavras-chave:}

Resíduos industriais, fosfogesso, reciclagem

\section{Introdução}

A indústria de fertilizantes enfrenta problemas com a quantidade de resíduos gerados na produção de ácido fosfórico, sendo, aproximadamente, 4 vezes maior do que a quantidade de fertilizante produzida ${ }^{1}$. Esse resíduo, conhecido como fosfogesso, possui propriedades físicas e químicas similares ao gesso comercial para a construção civil (fabricado a partir do minério gipso). O objetivo da pesquisa foi analisar o comportamento do fosfogesso em diversos períodos de calcinação para avaliar seu comportamento sem alteração de suas características e avaliar o melhor período de calcinação. Para tanto, o resíduo passou pelos processos de moagem secagem e calcinação. Foram escolhidos 3 diferentes períodos no forno: 1hora (FG1), 2horas (FG2) e 5 horas (FG5) na mesma temperatura $\left(150^{\circ} \mathrm{C}\right)$. Foram realizados ensaios físicos (massa unitária, tempo de pega) e ensaios mecânicos (dureza, resistência à compressão). Os corpos de prova foram rompidos com 28 dia.

\section{Resultados e Discussão}

Os resultados de massa unitária e dos tempos de pega estão dispostos nas Tabelas 1 e 2, e a resistência à compressão e a dureza estão apresentadas nas Figuras 1 e 2 , respectivamente.

Tabela 1. Massa Unitária

\begin{tabular}{|c|c|}
\hline \multicolumn{2}{|c|}{ Massa Unitária ABNT NBR 13207: $>\mathbf{7 0 0 ~} \mathbf{~ g} / \mathbf{m}^{\mathbf{2}}$} \\
\hline Amostra & Massa Unitária \\
\hline FG1 & 439,54 \\
\hline FG2 & 562,68 \\
\hline FG5 & 594,07 \\
\hline GC & 470,65 \\
\hline
\end{tabular}

Tabela 2. Tempo de pega

\begin{tabular}{|c|c|c|c|c|c|}
\hline \multicolumn{7}{|c|}{ Tempo de pega } \\
\hline Pastas & Início & Fim & Pastas & Início & Fim \\
\hline FG1 & 4 & 18 & FG5 & 13 & 32 \\
\hline FG2 & 5 & 21 & GC & 18 & 30 \\
\hline
\end{tabular}

A massa unitária aumentou com 0 tempo de permanência no forno. Como o produto da calcinação é o hemi-hidrato, que tem densidade menor do que o dihidrato, o FG5 teve modificações na microestrutura para obter maior densidade.
Os tempos de pega aumentaram com o tempo de calcinação, sendo que o FG5 foi o que mais se aproximou do gesso comercial.

Gráfico 1. Resistência à Compressão.

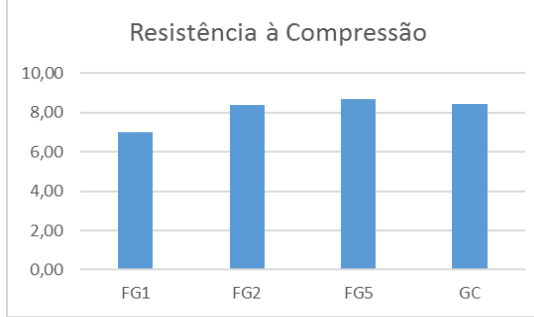

Gráfico 2. Dureza.

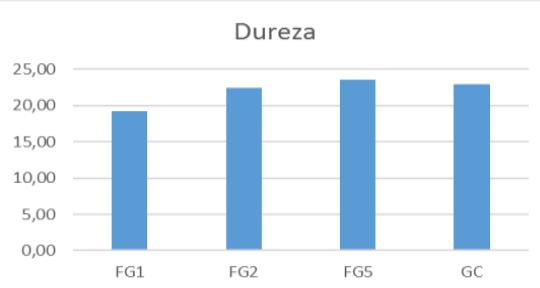

Os fosfogessos FG2 e FG5 tiveram resistência à compressão e dureza compatíveis com o gesso comercial. Assim, para economia de energia na reciclagem, o FG2 seria o material mais adequado para uso na construção civil. Embora tenha tempo de pega mais rápido, poderá ser utilizado na fabricação de componentes.

\section{Conclusões}

Conclui-se que há a viabilidade na reciclagem do resíduo de fosfogesso para ser utilizado na construção civil com tempo de permanência no forno de 2 horas. O estudo precisa ter continuidade para que outras propriedades sejam avaliadas.

\section{Agradecimentos}

Agradeço aos técnicos do laboratório LARES, pelo suporte técnicos, e as alunas Luana Ribeiro e Tamires Epiphanio, e ao CNpq pela oportunidade.

ASSOCIAÇÃO BRASILEIRA DE NORMAS TÉCNICAS. Gesso para construção - Determinação das propriedades físicas da pasta: NBR-12128, Rio de Janeiro, 2017.

CAMARINI, Gladis . Curing Effects on Air Permeability of Concrete. Advanced Materials Research, v. 214, p. 602-606, 2011.

FERRARI, F. O. S. 2012. UTILIZAÇÃO DE FOSFOGESSO, RESÍDUOS DA PRODUÇÃO DE CAL E AREIA DÁ EXTRAÇÃO DE OURO. 2012.

PEREIRA, Valdir M.; CAMARINI, Gladis . Air Permeability of Concrete by Thenoz Method. Advanced Materials Research, v. 224, p. 132-136, 2011 